\title{
EFFICACY AND SAFETY OF RADIATION SYNOVECTOMY WITH YTTRIUM-90: A RETROSPECTIVE LONG-TERM ANALYSIS OF 164 APPLICATIONS IN 82 PATIENTS
}

\author{
G. STUCKI, P. BOZZONE, E. TREUER, P. WASSMER and M. FELDER \\ Rheumaklinik und Institut für Physıkalische Therapie, Universitätsspital Zürich, Zürich, Switzerland
}

\begin{abstract}
SUMMARY
In this long term retrospective study of radiation synovectomy with Yttrium-90 (Y90), we evaluated the results of 164 applications in 82 patients with RA, OA with synovitis, ankylosing spondylitis and psoriatic arthritis. Radiation synovectomy with Y 90 has an overall success rate of approximately $50 \%$ and is therefore an effective alternative to surgical synovectomy in chronic synovitis which fails to respond to conservative treatment. Elbow and knee responded significantly better than shoulder and ankle joints. Patients with radiological stages from 0 to 2 showed a significantly better success rate than those with stage 3 changes. In responders, repeat therapy for recurrence of symptoms or treatment of a symptomatic corresponding symmetrical joint is advisable. Repeat therapy in a previous non-responder is associated with an unacceptably high failure rate. Therefore, when a joint fails to respond after 6 months, arthroscopy should be performed to evaluate further treatment procedures. A successful result was found in only 11 of 25 joints treated with arthroscopic synovectomy followed by radiation synovectomy within 2 weeks, indicating no benefit of this combination.
\end{abstract}

Key words: Radiosynoviorthesis, Rheumatoid arthritis, Osteoarthritis, Psoriatic arthritis, Ankylosing spondylitis.

Chronic synovitis, unresponsive to systemic medical therapy including anti-inflammatory drugs and remission inducing agents and intra-articular administration of corticosteroids, can be treated with synovectomy. Since 1963, when Ansell and co-workers [1], based on experience of radiation pleurodesis [2] reported the first study of intra-articular radiocolloids in the treatment of persistent knee effusion, radiation synovectomy has been shown to be an effective alternative to surgical synovectomy without its risks [3] and to be an alternative to chemical synovectomy with osmic acid [4].

In order to minimize the biological hazards, radioactive gold was substituted with Yttrium-90 (Y90) [5-8]. Y90 has the advantage of being a pure beta-emitter, having greater soft tissue penetration and a larger particle size with correspondingly much less accumulation of Y90 in regional lymph nodes. Immobilization of the treated limb was found to be another effective measure reducing leakage to the regional lymph nodes [9].

The aim of our retrospective long term analysis of 164 radiation synovectomies was to evaluate the efficacy and safety of radiation synovectomy with $\mathrm{Y} 90$ and to determine which factors influence a successful outcome.

\section{PATIENTS AND METHODS}

Between 1979 and 1989 a total of 164 joints in 82 patients were treated with intra-articular injection of Y90. There were 44 women and 38 men, with a mean age of 40.5 years (range $20-77$ years). The diagnoses and the joints treated are shown in Table I. The mean duration of the disease before therapy was 7.8 years. All patients had active and persistent synovitis of the treated joint of

Submitted 4 December 1991; revised version accepted 10 April 1992.

Correspondence to: G. Stucki, Department of Rheumatology, University Hospital, Gloriastrasse 25, CH-8091 Zürich, Switzerland. more than 6 months duration refractory to anti-inflammatory medication disease-modifying drugs (patients with RA) and intra-articular steroid therapy. Twentyfive joints had undergone arthroscopic synovectomy 14-18 days before synovirothesis [10].

The doses of Y90 used in the study were $6 \mathrm{mCi}$ for the knee joint, $3 \mathrm{mCi}$ for the shoulder and the hip and $2 \mathrm{mCi}$ for the ankle and the elbow [11]. Two days before the synoviorthesis the effusion was tapped and $40 \mathrm{mg}$ triamcinoloneacetonide was injected. Y90 was injected under local anaethesia after controlling for the correct intra-articular position of the needle by contrast media and image amplification. To prevent transient local reaction and to clear the needle from the nuclide before withdrawing the needle, a further injection of $40 \mathrm{mg}$ triamcinoloneacetonide was given. Imaging of activity distribution over the joint, the groin, the aortic lymph nodes and the liver with a large field gamma-camera was performed immediately, 24 and $48 \mathrm{~h}$ after intra-articular injection of $Y 90$ in 120 of the 164 joints treated with radiation synovectomy. In order to minimize systemic distribution of the radioactive agent the patients with synoviorthesis of the lower limb were bed rested for 3 days after injection [9], patients with treatment of the upper limb had to wear an arm sling. During the period of bed rest, the patients were treated by a physiotherapist who performed an antithrombotic exercise programme twice a day.

In retrospective clinical evaluation, results were classified according to the patients subjective assessment as excellent, good, fair or poor. Patients with an excellent result had complete pain relief and no joint effusion, patients with a good result had almost complete relief of pain and little joint effusion for at least 1 year. Patients with a fair result had partial symptomatic relief and a diminished joint swelling, patients with a poor result had no benefit from the treatment resulting 
TABLE I

Clinical Diagnosis and Joints Treated

\begin{tabular}{lccccccc}
\hline Diagnosis & No. of patients & Joints & Knee & Ankle & Shoulder & Elbow & Hip \\
\hline Seropositive RA & 40 & 105 & 57 & 18 & 18 & 9 & 3 \\
Seronegative RA & 14 & 22 & 15 & 3 & 3 & 1 & 0 \\
Monarthritis & 5 & 5 & 4 & 1 & 0 & 0 & 0 \\
PsA & 8 & 8 & 3 & 1 & 3 & 0 & 0 \\
AS & 3 & 5 & 5 & 0 & 0 & 0 \\
Oligoarthritis & 11 & 17 & 17 & 0 & 0 & 0 \\
OA & 82 & 164 & 103 & 23 & 24 & 11 \\
\hline Total & & & & & & 3 \\
\hline
\end{tabular}

in continued pain and swelling. Excellent and good were considered as success, fair and poor as failure. Furthermore a clinical, laboratory and radiological evaluation according to Larsen et al. [12] was performed to assess clinical status and functional capacity.

\section{RESULTS}

Table II shows the overall results 1 year after radiation synovectomy as stated by the patient at the time of retrospective clinical evaluation. Improvement was noted in $60 \%$ with a good or excellent result in $48 \%$. Therefore successful synoviorthesis was seen in $48 \%$. A marked difference was found depending on the joints treated and depending on the underlying disease process. Elbow and knee responded significantly better, shoulder and ankle significantly less well $(P<0.046$, Kruskal-Wallis analysis) (Fig. 1). Significantly better results than in PsA were obtained in patients suffering from AS $(P<0.04$, two-sample test $)$ and $\mathrm{OA}(P<0.034)$. The results for RA did not differ significantly from the other groups and there was also no significant difference between seronegative and seropositive RA (Fig. 2).

Figure 3 shows the percentage of RA patients presenting with little or no pain or effusion (successes) at the time of clinical evaluation as a function of the time since the synoviorthesis. There was a marked decline in the success rate at year 3 and up to 7 years after therapy we found a persistent good or excellent result in about $20 \%$ of cases.

Age was not a predictor of the result. In patients with RA under the age of 55,30 successes and 34 failures were noted, whereas over the age of 56,30 successes and 33 failures were obtained revealing no difference.

Activity of the disease process at the time of clinical evaluation (RA patients, 127 joints), measured by patients self-assessment, Ritchie index and erythrocyte sedimentation rate showed no significant difference between the successes and failures in the two sample tests. Because of the reported low response rate in advanced radiological stages, radiation synovectomy in stages 3 and 4 was performed only six and two times respectively. We found a clearly better success rate in patients with Larsen stage $0(60.9 \%), 1(61.5 \%)$ and 2 $(33.3 \%)$ than $3(16.7 \%)$ prior to therapy $(P<0.097$, two sample test). In 75 cases of RA where a control X-ray could be performed, 56 showed no progression whereas a progression of one stage was seen in 11 and two stages in eight applications.

A significant difference in the success rate between patients with no limitation in range of motion, patients with little and patients with marked functional limitation at the time of clinical evaluation was found $(P<0.0003$, Kruskal-Wallis analysis).

The 25 cases who had undergone arthroscopic synovectomy before radiation synovectomy showed a success rate of $44 \%$ indicating no significant difference compared to the joints without this treatment.

Fourteen joints underwent a second radiation synovectomy. In the five joints with a previous success (responders) a constantly good outcome was achieved, whereas in the nine cases with an initial failure, success at the second attempt was only seen twice.

In 43 cases of a time parallel therapy of two different joints (39 cases on symmetric joints) in the same patient, the outcome differed in only four cases.

Imaging of activity distribution with a large field gamma-camera showed a homogeneous activity distribution in 111 cases, whereas only four had an irregular

TABLE II

Successes and Fallures 1 Year After Radiation Synovectomy as Stated by the Patient at the Time of the Retrospective Clinical Evaluation. (First column: successes; second column: failures)

\begin{tabular}{|c|c|c|c|c|c|c|c|c|c|}
\hline \multirow{2}{*}{$\frac{\text { Diagnosis }}{\text { Seropositive RA }}$} & \multicolumn{2}{|c|}{ Knee } & \multicolumn{2}{|c|}{ Ankle } & \multicolumn{2}{|c|}{ Shoulder } & \multicolumn{2}{|c|}{ Elbow } & \multirow{2}{*}{$\frac{\text { Success }}{46}$} \\
\hline & 30 & 27 & 4 & 14 & 5 & 13 & 8 & 1 & \\
\hline Seronegative RA & 9 & 6 & 0 & 3 & 2 & 1 & 1 & 0 & 54.5 \\
\hline Monarthritis & 1 & 3 & 0 & 1 & & & & & 20 \\
\hline PsA & 1 & 2 & 0 & 1 & 0 & 3 & 0 & 1 & 12.5 \\
\hline As & 4 & 1 & & & & & & & 80 \\
\hline Oligoarthritis & 0 & 2 & & & & & & & 0 \\
\hline$O A$ & 12 & 5 & & & & & & & 71 \\
\hline Success rate & 55.3 & & 29 & & 17 & & 82 & & 48 \\
\hline
\end{tabular}




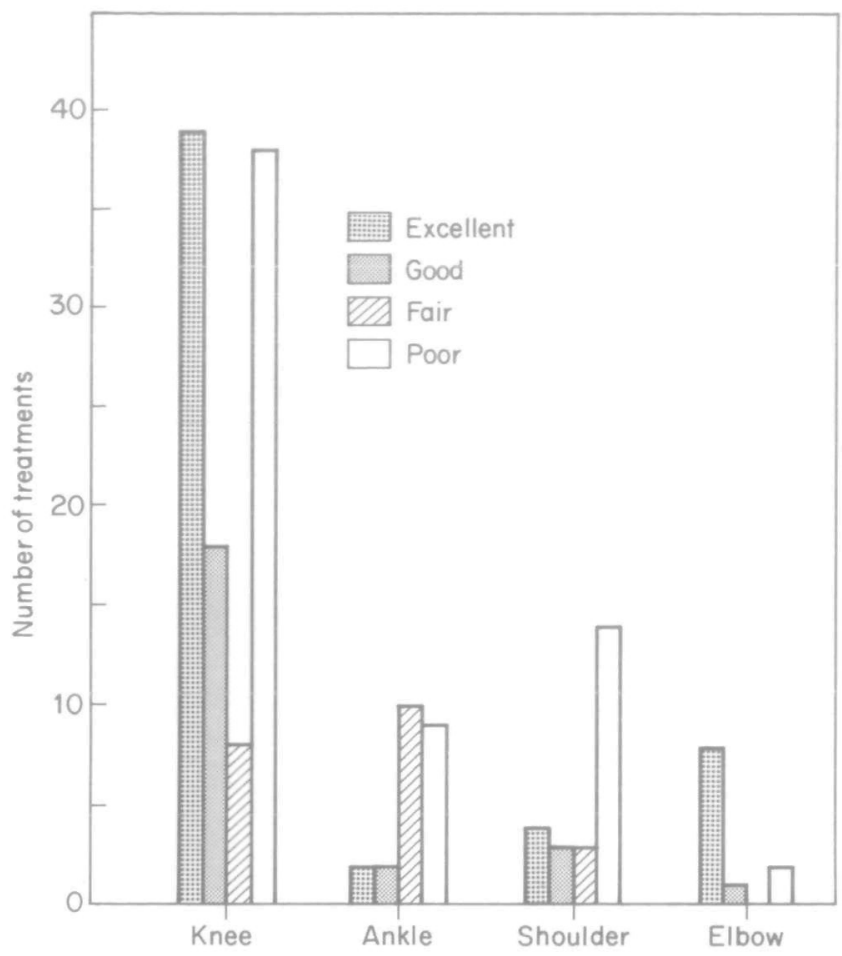

Fig. 1.- Results 9 months after radiation synovectomy as stated by the patient for the knee, the ankle, the shoulder and the elbow joint.

activity distribution; a hot spot was detected in three cases and no intra-articular distribution at all was found

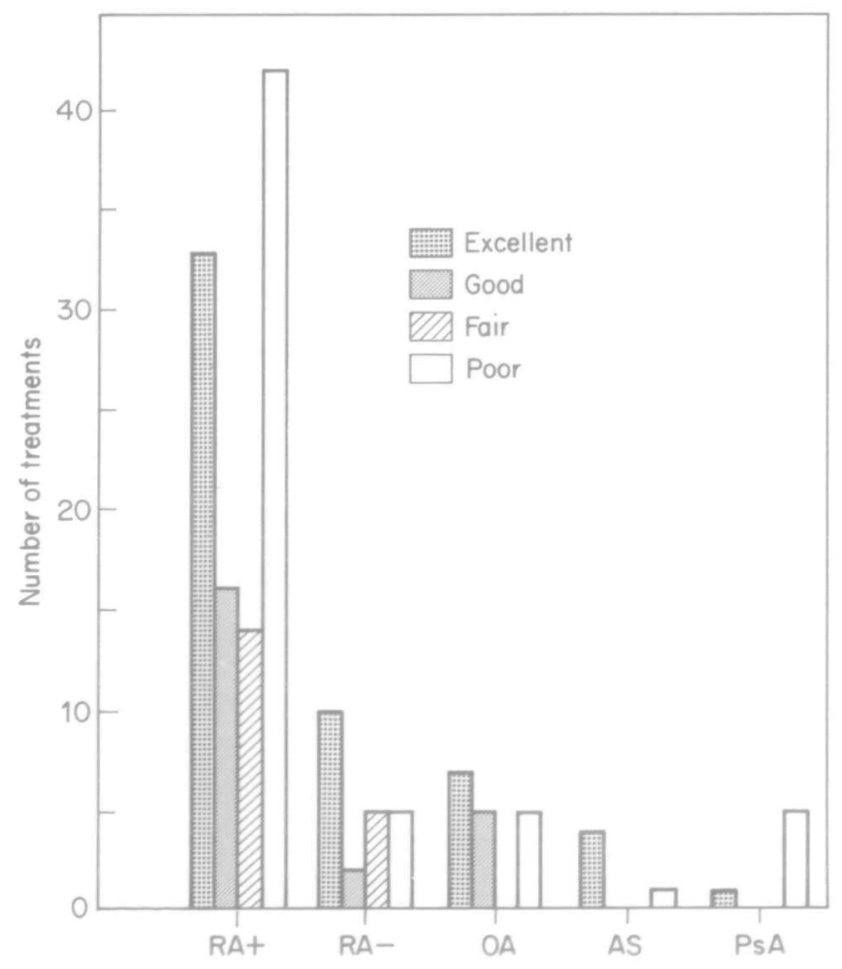

FIG. 2.-Results 9 months after therapy as stated by the patient for seropositive rheumatoid arthritis (RA+), seronegative RA (RA-), osteoarthritis (OA), ankylosing spondylitis (AS) and psoriatic arthritis (PsA). in two cases. No radiation leakage over the groin, the aortic lymph nodes and the liver was detected.

The success rate was $55 \%$ with regular distribution but there was only one successful outcome in the four cases with irregular distribution; of the three cases with a hot spot two were successful and as expected the two joints showing no intra-articular distribution were both failures. No radiation-induced problems at the site of injection or other important complications were observed. There was no local or systemic malignancy induction in the 82 patients controlled, which add up to 307 patient years. Fourteen of 62 knee joints controlled by X-ray showed a subpatellar calcification; 12 of these cases had a homogeneous intra-articular distribution in the scintigraphic control whereas two showed a hot spot [13].

\section{DISCUSSION}

Previous studies have demonstrated the efficacy of radiation synovectomy with Y 90 and the statistically significant superiority of $Y 90$ to saline, non-radioactive yttrium and corticosteroids $[14,15]$ in the treatment of the large and medium sized joints in RA, PsA and OA $[16,18]$.

The results found in our study with an overall success rate in $48 \%$ and excellent response rates in OA and AS are similar to the response rates reported in the literature $[16,19]$. The high failure rate in the few patients with PsA may have been influenced by the low response rate of the treated joints (one ankle and three shoulder joints).

There is a remarkable difference between the different joints treated. Similar to Menkes et al. [16], we found a high success rate in the treatment of the elbow and the knee joint but poor results in the shoulder and ankle joints. The poor result in the shoulder joint may be due to the pathologically important involvement of the rotator cuff usually present, which is not influenced by synoviorthesis.

The question of a repeat therapy arises when a first injection has shown a poor result or when there is recurrence of symptoms after an initial response. It is impor-

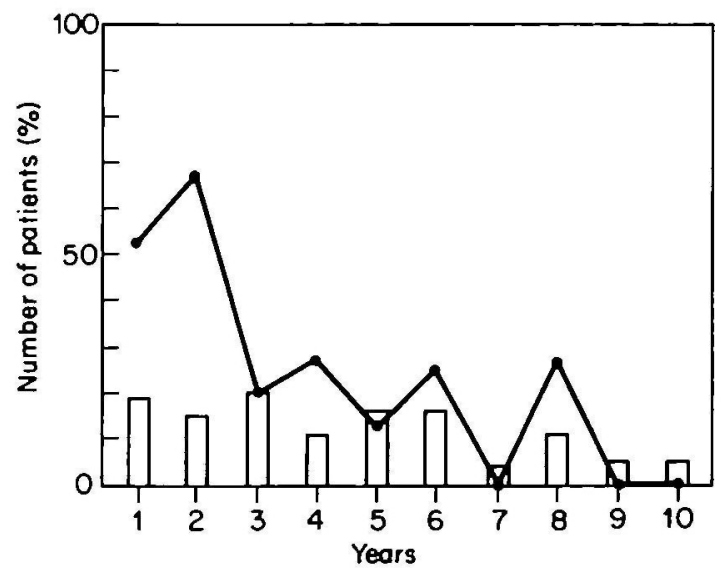

Fig. 3.-Percentage of RA patients with little or no pain and effusion (successes) at the time of clinical evaluation as a function of the time since radiation synovectomy (year groups). The bars show the number of applications in each group. 
tant to note, that one can reasonably predict at 6 months whether the treatment is going to succeed or fail [16] and therefore plan a further injection or a surgical synovectomy at that stage. We found it worthwhile repeating injection in an initially responding joint, whereas in nonresponders the chance of success at the second attempt is limited confirming the results of Winfield and Gumpel [20]. In these cases an arthroscopic evaluation is advisable to investigate the cause of the failure and adapt treatment accordingly. With severe cartilaginous lesions, performing a second synoviorthesis would seem worthless and operative measures such as prosthetic surgery could be planned. In the case of fibrinonecrotic deposits, found especially in severe fibrin-producing hypertrophic synovitis, arthroscopy could be used to wash out the deposits and to abrade the remaining synovial tufts [21]. If failure is due to technical reasons such as lack of activity, revealed by a scintigraphic control, the procedure can be repeated immediately.

Interestingly we found a high correlation in the treatment of symmetric joints, making treatment of the corresponding symptomatic joint favourable. A previous arthroscopic synovectomy to remove as much of the proliferative synovium as possible in order to improve the effect of the radionuclide on the remaining synovium [10], was associated with a success rate of not more than $44 \%$. This moderate success rate differs to a considerable extent from the excellent results reported for arthroscopic synovectomy as a single procedure [22-24] or after failure of radiation synovectomy [25]. Further studies are needed to evaluate arthroscopic synovectomy followed by radiation synovectomy compared to radiation synovectomy or arthroscopic synovectomy alone. The optimal time interval may be longer than the 1 to 2 weeks reported in this study. In addition the selection of patients for this combined procedure might be important.

In conclusion we can say, that radiation synovectomy with Y90 is a safe and useful instrument in the therapeutic strategy for patients with RA, OA and AS.

\section{REFERENCES}

1. Ansell B, Crook A, Mallard JR, Bywaters GLE. Evaluation of intra-articular colloidal gold $\mathrm{Au}-198$ in the treatment of persistent knee effusions. Ann Rheum Dis 1963;22:435-9.

2. Andrews GA, Root SW, Kniseley RM. Metabolism and distribution fo colloidal $198 \mathrm{Au}$ injected into serous cavities for treatment of effusions associated with malignant neoplasms. Cancer 1953;6:294.

3. Gumpel JM, Roles NC. A controlled trial of intra-articular radiocolloids versus surgical synovectomy in persistent synovitis Lancet 1975;1:488-9.

4. Nissilä M, Anttila P, Hämäläinen M, Jalava S. Comparison of chemical, radiation and surgical synovectomy for knee joint synoitis. Scand J Rheumatol 1978;7: 225-8.

5. Virkkunen M, Krusius FE, Heiskanen T. Experiences of intra-articular administration of radioactive gold. Acta Rheum Scand 1967;13:81-91.

6. Delbarre F, Cayla J, Menkes C, Aignan A, Roucayrol $\mathrm{JC}$, Ingrand J. La synoviorthèse par les radio-isotopes. Presse med 1968;76:1045-51.
7. Gumpel JM, Beer TC, Crawley JCW, Farran HEA. Yttrium 90 colloids in persistent synovitis of the $\mathrm{knee}$. A single-centre comparison of four radiocolloids. Br J Radiol 1975;48:377-81.

8. Dolphin GW. Biological hazards of radiation. Ann Rheum Dis 1973;32(suppl):23-8.

9. Williams PM, Crawley JCW, Freeman AM, Lloyd DC, Gumpel JM. Feasibility of outpatient management after intra-articular yttrium-90: comparison of two regimens. $B M J 1981 ; 282: 13-14$.

10. Gschwend N. Chemical and radiation synovectomy. In: Kelley WN, ed. Textbook of rheumatology. Philadelphia; WB Saunders, 1989;1953-61.

11. Kerschbaumer F, Pfaller K, Siorpaes R. Neuere Aspek te zur Radiosynoviorthese des Kniegelenkesklinische und experimentelle Ergebnisse. Akt Rheumatol 1987;12:143-6.

12. Larsen A, Dale K, Eek M. Radiographic evaluation of rheumatoid arthritis and related conditions by standard reference films. Acta Radiol Diag 1977;18: $481-91$

13. Stucki G, Bozzone B, Treuer E, Wassmer P, Felder M. Subpatellar calcification after radiation synovectomy with Yttrium 90; submitted.

14. Delbarre F, Le Go A, Menkes CJ, Aignan M. Preuve par étude statistique en double aveugle de l'effet therapeutique d'un colloide chargé d'yttrium 90 dans l'arthrite rheumatoid en genou. C R Acad Sci [III] 1974;279:1051-4.

15. Bridgman JF, Bruckner F, Eisen V et al. Irradiation of the synovium in the treatment of rheumatoid arthritis. Am J Med 1973;42:357-67.

16. Menkes CJ, Aignan M, Galmiche B, Le Go A. Le traitment des rhumatismes par les synoviortheses choix des malades, choix des articulations, modalités practiques, resultats, indications, contreindications. Rheumatologie 1972;2(suppl):61-78.

17. Rosenthall $L$. Use of radiocolloids for intra-articular therapy for synovitis. In: Spencer RP, ed. Therapy in nuclear medicine; New York: Grune and Stratton, 1978.

18. Szanto E. Long-term follow-up of Y90 treated knee joint arthritis. Scand J Rheumatol 1977;6:209-12.

19. Recordier AM, Roux H, Alberti J, Dehame R, Paulin R, Bernard PA. Notre experience de synoviorthèses en rhumatologie. Rhumatologie 1972; 2(suppl):107-11.

20. Winfield J, Gumpel JM. An evaluation of repeat intraarticular injections of yttrium-90 colloids in persistent synovitis of the knee. Ann Rheum Dis 1979;38: $145-7$.

21. Guyadier-Souquieres C, Beguin J, Ollivier D, Loyau G. Knee arthroscopy after yttrium or osmic acid injection. Arthroscopy 1989;5:70-5.

22. Cleland LG, Treganza R, Dobson P. Arthroscopic synovectomy; a prospective study.J Rheumatol 1986;13: 907-10.

23. Cohen S, Jones R. An evaluation of the efficacy of arthroscopic synovectomy of the knee in rheumatoid arthritis: 12-24 months results. $J$ Rheumatol 1987;14: $452-5$.

24. Altman RD, Gray RG, Diagnostic and therapeutic uses of the arthroscope in rheumatoid arthritis and osteoarthritis. AmJ Med 1983;76:50-5.

25. Combe B, Krause E, Sany J. Treatment of chronic knee synovitis with arthroscopic synovectomy after failure of intra-articular injection of radionuclide. Arthritis Rheum 1989;32:10-14. 